\title{
STUDY OF ZIRCALOY-4 CLADDING AIR DEGRADATION AT HIGH TEMPERATURE
}

\author{
Marina Lasserre \\ IRSN, ENSM-SE \\ Saint Paul lez Durance, France \\ Véronique Peres \\ ENSM-SE \\ Saint-Etienne, France
}

\author{
Olivia Coindreau \\ IRSN \\ Saint Paul lez Durance, France
}

\author{
Michel Mermoux \\ LEPMI- Phelma Campus \\ Saint Martin d'Hères, France
}

\author{
Michèle Pijolat \\ ENSM-SE \\ Saint-Etienne, France
}

\author{
Jean-Paul Mardon \\ AREVA-NP \\ Lyon, France
}

\section{ABSTRACT}

Zircaloy cladding, providing the first containment of $\mathrm{UO}_{2}$ fuel in Pressurised Water Reactors, can be exposed to air during accidental situations. This might occur during reactor operation (in case of a core meltdown accident with subsequent reactor pressure vessel breaching), under shutdown conditions with the upper head of the vessel removed, in spent fuel storage pools after accidental loss of cooling or during degraded transport situations. The fuel assemblies inadequately cooled, heat up and as a result, corrosion of Zircaloy claddings takes place. This paper is devoted to the kinetic analysis of $\mathrm{Zy} 4$ corroded at $850^{\circ} \mathrm{C}$ in $20 \%$ oxygen - $80 \%$ nitrogen partial pressure atmosphere to support the comprehension of the degradation mechanisms involved during the post-transition stage.

\section{INTRODUCTION}

Experimentally, it has been shown that corrosion in air of Zy4 cladding is faster than corrosion in oxygen or in steam [1-4]. Between $700^{\circ} \mathrm{C}$ and $1050^{\circ} \mathrm{C}$, kinetic curves obtained by thermogravimetry reveal two stages: a pre-transition and a post-transition one. It is known that the oxide growth during the pre-transition stage is controlled by oxygen vacancy diffusion in the oxide layer, since neither oxygen nor nitrogen partial pressures influence the kinetics. During the post-transition stage, it has been concluded that presence of nitrogen in the atmosphere has an accelerating effect on the kinetic rate only above $700^{\circ} \mathrm{C}$ but the corresponding mechanism has not been identified yet [5].

In the literature, several sequences of events have been proposed to explain these two stages. According to [6-8], during the pretransition stage, oxide forms first and zirconium nitride $(\mathrm{ZrN})$ precipitate close to the metal-oxide interface by the dissolution of nitrogen into zirconia. Since the oxide continues to form preferentially, oxygen reacts with the nitride to form porous zirconia. This reaction results in a volume increase and formation of cracks in the zirconia outer scale, allowing free access of the reacting gas to the metal surface, it is the kinetic transition. Then, the same sequence of events happens during the post-transition stage until the metal is entirely consumed.

Recent results of [9] suggest that zirconium oxynitrides are also present for temperatures between $800-1000^{\circ} \mathrm{C}$. Indeed according to high temperature studies of nitrogen incorporation into the zirconia sublattice made in [10-19], depending on the amount of nitrogen into the zirconia, substoichiometric monoclinic, tetragonal or cubic zirconia are stabilized as well as various phases of zirconium oxynitride.

Results presented in [1-4] show that another possibility to describe nitriding and fast degradation of Zy4 cladding is that oxide forms first but kinetic transition occurs due to the release by cracks of compressive stresses build-up in the oxide while its thickness increases. As a matter of fact, gases have direct access to the metal and oxygen is consumed first at the bottom of the cracks, creating a local oxygen starvation. Then, nitrogen reacts with $\alpha-\mathrm{Zr}(\mathrm{O})$ or substoichiometric zirconia phases and converts to a $\mathrm{ZrO} \mathrm{Z}_{2} \mathrm{ZrN}$ twophases mixture when the solubility limit is exceeded [20]. This reaction creates pores that are preferentially located along the $\mathrm{ZrN}$ precipitates. As the oxide grows inwards, the zirconium nitride is oxidized by fresh air flowing near the external surface. This reaction is followed by a volume increase leading to the formation of cracks in the oxide and giving direct access for the air to the metal.

Other studies of oxidation of $\mathrm{ZrN}$ presented in [21-24] show that the porous zirconia is not the only phase formed during the process. Indeed, zirconium oxynitride $\mathrm{Zr}_{2} \mathrm{ON}_{2}$ and stoichiometric zirconium nitride $\mathrm{Zr}_{3} \mathrm{~N}_{4}$ are also formed at $\mathrm{ZrO}_{2}-\mathrm{ZrN}$ interface. According to 
the authors, the orthorhombic structure of $\mathrm{Zr}_{3} \mathrm{~N}_{4}$ allows the formation of $\mathrm{Zr}_{2} \mathrm{ON}_{2}$ at $\mathrm{ZrO}_{2}-\mathrm{Zr}_{3} \mathrm{~N}_{4}$ interface and $\mathrm{ZrN}$ corresponds to substoichiometric $\mathrm{Zr}_{3} \mathrm{~N}_{4}$ (i.e. with a high activity of nitrogen vacancy).

This paper describes first corrosion kinetics of small thin plates of $\mathrm{Zy} 4$ in $20 \% \mathrm{O}_{2}-80 \% \mathrm{~N}_{2}$ mixture at $850^{\circ} \mathrm{C}$ as well as morphological observations. A kinetic analysis of the corrosion process is then made and finally, results obtained are discussed in order to propose a mechanism process of corrosion in nitrogen and oxygen partial pressures mixtures.

\section{EXPERIMENTAL}

\section{1. $\underline{\text { Sample }}$}

Specimens of Zy4, whose chemical composition is given below, were provided by AREVA-NP and cut to $10 \mathrm{~mm} \times 10 \mathrm{~mm}$ for the corrosion tests. The bare sample is cleaned in acetone and dried.

\begin{tabular}{cccccc}
\hline $\begin{array}{c}\text { Alloy } \\
(\text { wt. \%) }\end{array}$ & Sn & Fe & O & Cr & $\begin{array}{c}\mathrm{C} \\
(\mathrm{ppm})\end{array}$ \\
\hline Zy4 & $1.32-1.35$ & 0.21 & $0.123-0.129$ & 0.11 & $125-140$ \\
\hline
\end{tabular}

\section{Thermogravimetric apparatus}

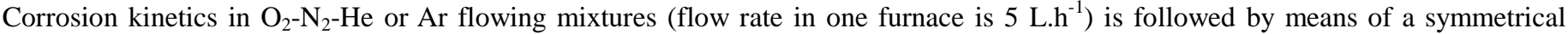
microbalance (SETERAM-TAG24) equipped with thermoregulated cooling fluid. Whereas the sample is suspended to an alumina rod, a specific alumina plate sample has been designed and placed in the reference furnace in order to minimise baseline shifts during experiments. Partial pressures in $\mathrm{O}_{2}$ and $\mathrm{N}_{2}$ are adjusted to the desired values thanks to mass flow meters. The total pressure in the apparatus is one atmosphere.

Corrosion tests presented in this paper are conducted at $850^{\circ} \mathrm{C}$ after a heating ramp of $10^{\circ} \mathrm{C} \cdot \mathrm{min}^{-1}$. Desired reactive gases (oxygen and nitrogen mixtures) are introduced at the beginning of the experiment (ambient temperature).

Small thin plates are used in order to maintain constant gas partial pressure along the entire sample surface.

\section{Characterization methods}

Techniques of optical microscopy, scanning electron microscopy, energy dispersive X-ray spectrometry with silicon drift detector, Xray tomography, high temperature X-ray diffraction, secondary ion mass spectrometry as well as Raman investigations have been used for morphological information.

For optical microscopy, SEM, EDX-SDD, HT-XRD and Raman characterizations, the corroded samples are cold embedded in resin 605 (methyl methacrylate) and polished with MECAPOL P320 PRESI device. Polishing is performed with ceramic papers and diamond pastes.

For SEM and EDX-SDD analyses, a fine carbon deposit is put on the surface of the sample.

For nanoSIMS analysis, the sample is embedded in Bakelite resin (with phenol). 


\section{EXPERIMENTAL RESULTS}

1. Corrosion of $\mathrm{Zy} 4$ in $20 \% \mathrm{O}_{2}-80 \% \mathrm{~N}_{2}$ at $850^{\circ} \mathrm{C}$
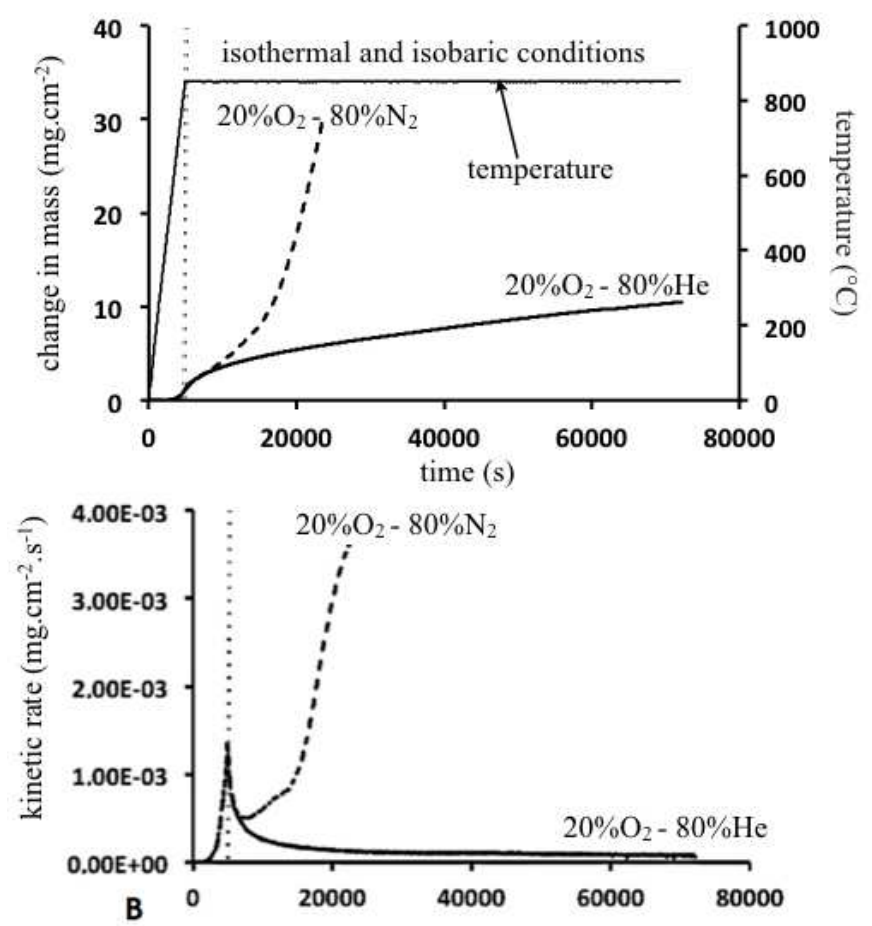

time (s)

Figure 1 - A: mass change as a function of time in $20 \% \mathrm{O}_{2}-80 \% \mathrm{~N}_{2}$ (dotted line) and in $20 \% \mathrm{O}_{2}-80 \%$ He (full line); $\mathrm{B}$ : kinetic rate as a function of time in $20 \% \mathrm{O}_{2}-80 \% \mathrm{~N}_{2}$ (dotted line) and in $20 \% \mathrm{O}_{2}-80 \%$ He (full line)

Figure 1A shows the change in mass curve as a function of time during an experiment in $20 \% \mathrm{O}_{2}-80 \% \mathrm{~N}_{2}$ and in $20 \% \mathrm{O}_{2}-80 \% \mathrm{He}$ atmospheres with the corresponding kinetic rate displayed in Fig 1B (it has been obtained by derivation of the change in mass versus time).

The change in mass at the beginning of the temperature plateau is $0,03 \%$ (Figure $1 \mathrm{~A}$ ) of the total mass gain after $6 \mathrm{~h}$ at $850^{\circ} \mathrm{C}$ and corresponds to the mass gained during the heating ramp. Once isothermal and isobaric conditions are reached, the kinetic rate decreases, which corresponds to the pre-transition stage. During this stage, the kinetic curves in $20 \% \mathrm{O}_{2}-80 \% \mathrm{~N}_{2}$ and in $20 \% \mathrm{O}_{2}-80 \%$ $\mathrm{He}$ are superimposed (Figure 1B). Consequently, the presence of nitrogen in the atmosphere seems to have no influence in the pretransition stage. Then, the reaction rate passes through a minimum for $20 \% \mathrm{O}_{2}-80 \% \mathrm{~N}_{2}$, corresponding to the kinetic transition. It can be clearly seen that the kinetic transition time is shorter for experiments realised in $20 \% \mathrm{O}_{2}-80 \% \mathrm{~N}_{2}$ atmosphere, at the end of the experiment it seems that no transition is seen for $20 \% \mathrm{O}_{2}-80 \% \mathrm{~N}_{2}$ on Figure 1. During the post-transition stage, nitrogen has an accelerating effect on the kinetic rate (Figure 1B).

Concerning the reproducibility of the curves (Figure 2), it has been noticed experimentally that the kinetic curves are very well superimposed until the kinetic transition but scattering of TGA traces is quite high during the post-transition stage. 

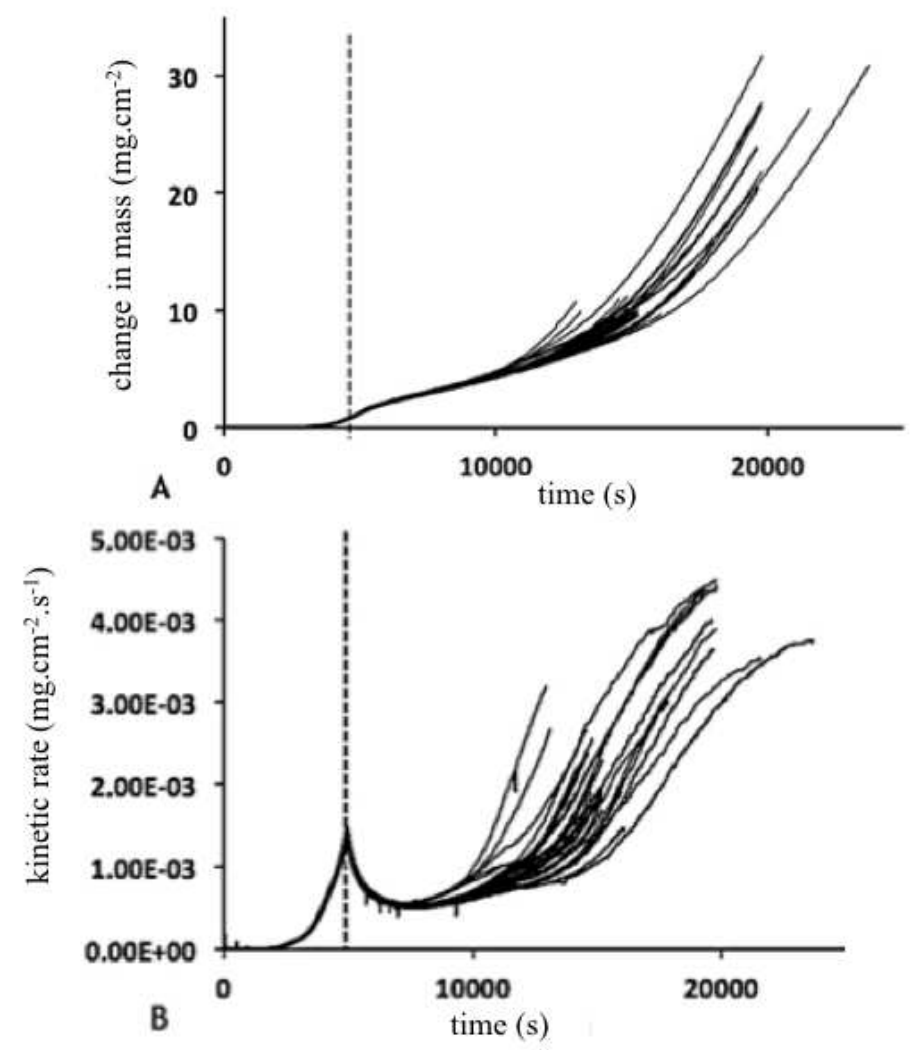

Figure 2 - Reproducibility during corrosion of $\mathrm{Zy} 4$ in $20 \% \mathrm{O}_{2}-80 \% \mathrm{~N}_{2}$; A: change in mass; B: kinetic rate

\section{Characterizations}

Morphological changes corresponding to the pre-transition stage (Figure 3A) and post-transition stage (Figure 3B) are shown bellow.

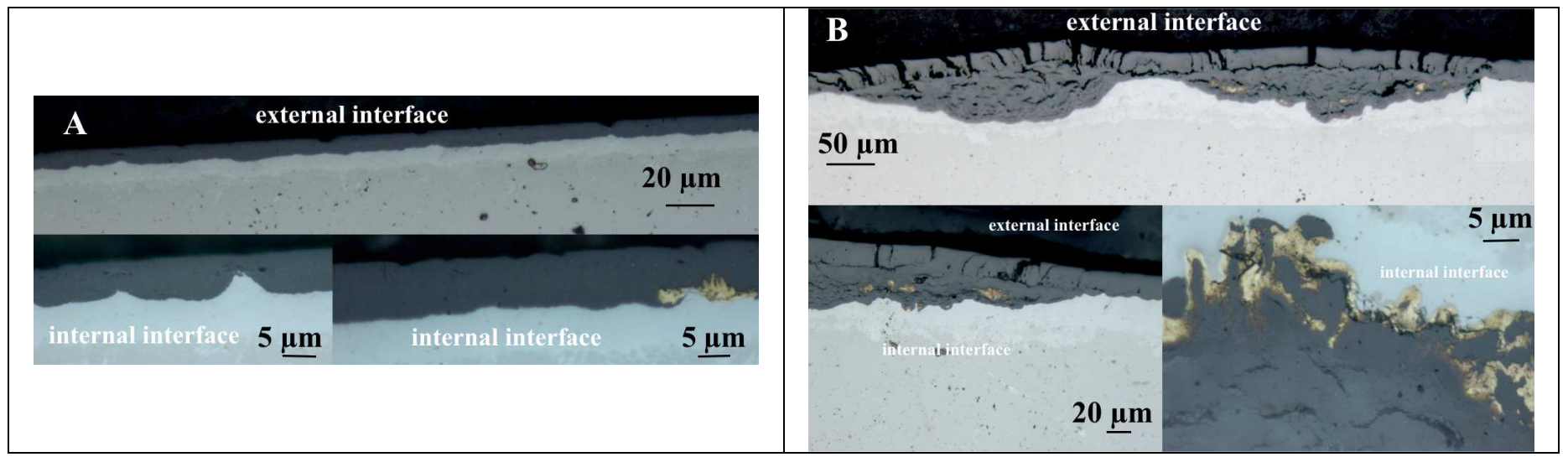

Figure $3-\mathrm{Zy} 4$ in $20 \% \mathrm{O}_{2}-80 \% \mathrm{~N}_{2}$ atmosphere during the pre-transition stage (A: mass gain of $1.76 \mathrm{mg}^{-\mathrm{cm}^{-2}}$ ) and during the post-transition stage (B: mass gain of $7.3 \mathrm{mg} . \mathrm{cm}^{-2}$ ); top: optical metallography with 100x magnification for $A$ and 50x magnification for B; bottom left: optical metallography with 1000x magnification for $A$ and 100x magnification for B; bottom right: optical metallography with 1000x magnification for $A$ and $B$

During the pre-transition stage, the protective oxide layer is dense and adherent to the metal. Some precipitates, whose colour is gold, are located at the metal-oxide interface and sometimes inside the protective oxide layer. In the literature, gold-coloured precipitates correspond to zirconium nitride [25]. The nature of those gold precipitates has been confirmed by Raman investigations (Figure 4). In addition, some cracks along the oxide layer are visible although the kinetic transition is not yet reached. 

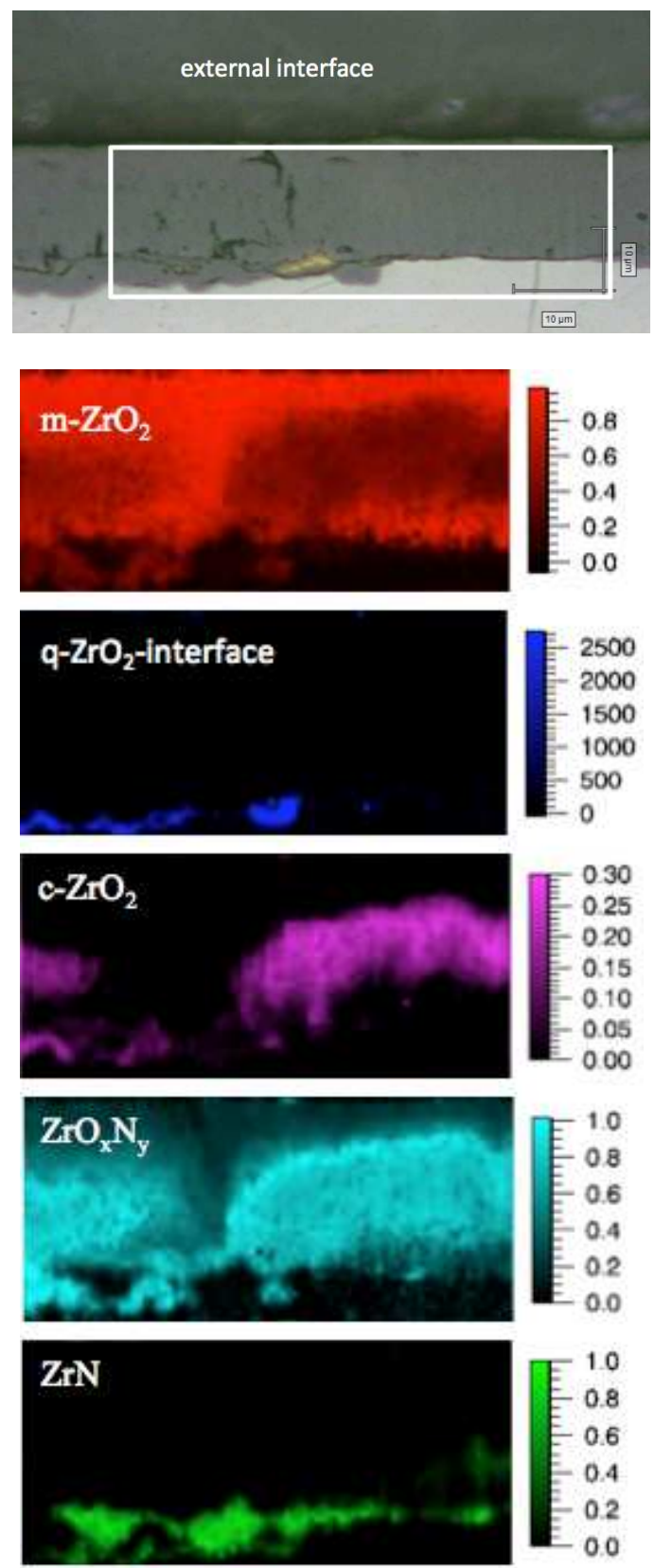

Figure 4 - Raman investigation during post-transition stage (mass gain of $7.3 \mathrm{mg.cm}{ }^{-2}$ ); top: area investigated; bottom: composition images of m-ZrO ${ }_{2}$, c$\mathrm{ZrO}_{2}, \mathrm{ZrO}_{\mathrm{x}} \mathrm{N}_{\mathrm{y}}$, and $\mathrm{ZrN}$ respectively, obtained from spectral decomposition, and integrated intensity of the $280 \mathrm{~cm}^{-1} \mathrm{q}_{-} \mathrm{ZrO}_{2}$ observed at the metal-oxide interface. See [26] for information of the protocol for the construction of the different images.

During the post-transition stage, it can be seen that the transition is a non-uniform process: the kinetic transition does not occur at the same time in the whole oxide layer. Corroded regions in the post-transition stage are characterized by large cracks perpendicular to the dense zirconia layer previously formed. Beneath the cracked oxide, the scale is porous and has cracks parallel to the surface sample. Moreover, some $\mathrm{ZrN}$ precipitates are clearly visible near the metal-oxide interface together with regions of dense zirconia layer. A brown colour scale can be noticed above $\mathrm{ZrN}$ precipitates. According to the literature nitrogen in solid solution stabilises $\mathrm{m}-\mathrm{ZrO}{ }_{2}$, $\mathrm{q}-$ $\mathrm{ZrO}_{2}$ and $\mathrm{c}-\mathrm{ZrO}_{2}$, consequently this brown colour scale could be either substoichiometric zirconia enriched with nitrogen in solid solution or, according to Raman investigations (Figure 4), a $\mathrm{ZrO}_{2}-\mathrm{ZrN}$ two phases mixture or $\mathrm{ZrO}_{\mathrm{x}} \mathrm{N}_{\mathrm{y}}$. For exemple, in the literature, $\mathrm{Zr}_{2} \mathrm{ON}_{2}$ zirconium oxynitride precipitate has a colour in optical microscopy close to that of $\mathrm{ZrN}$. 
NanoSIMS analysis, realised at Gabriel Lippmann public research centre, provided some answers not only concerning the nature of this brown colour scale but also regarding the phenomenon that could take place during the post-transition stage. The sample studied for this analysis has been corroded first in $20 \%{ }^{16} \mathrm{O}_{2}-80 \%{ }^{14} \mathrm{~N}_{2}$ during $4 \mathrm{~h}$ at $850{ }^{\circ} \mathrm{C}$ and then, ${ }^{16} \mathrm{O}$ has been switched with ${ }^{16} \mathrm{O}-7 \%$ in volume ${ }^{18} \mathrm{O}$ gases mixture during one hour. After this plateau, the temperature program has been stopped. ${ }^{18} \mathrm{O}$ and ${ }^{90} \mathrm{Zr}{ }^{14} \mathrm{~N}$ masses have been followed. Results obtained are displayed in Figure 5.
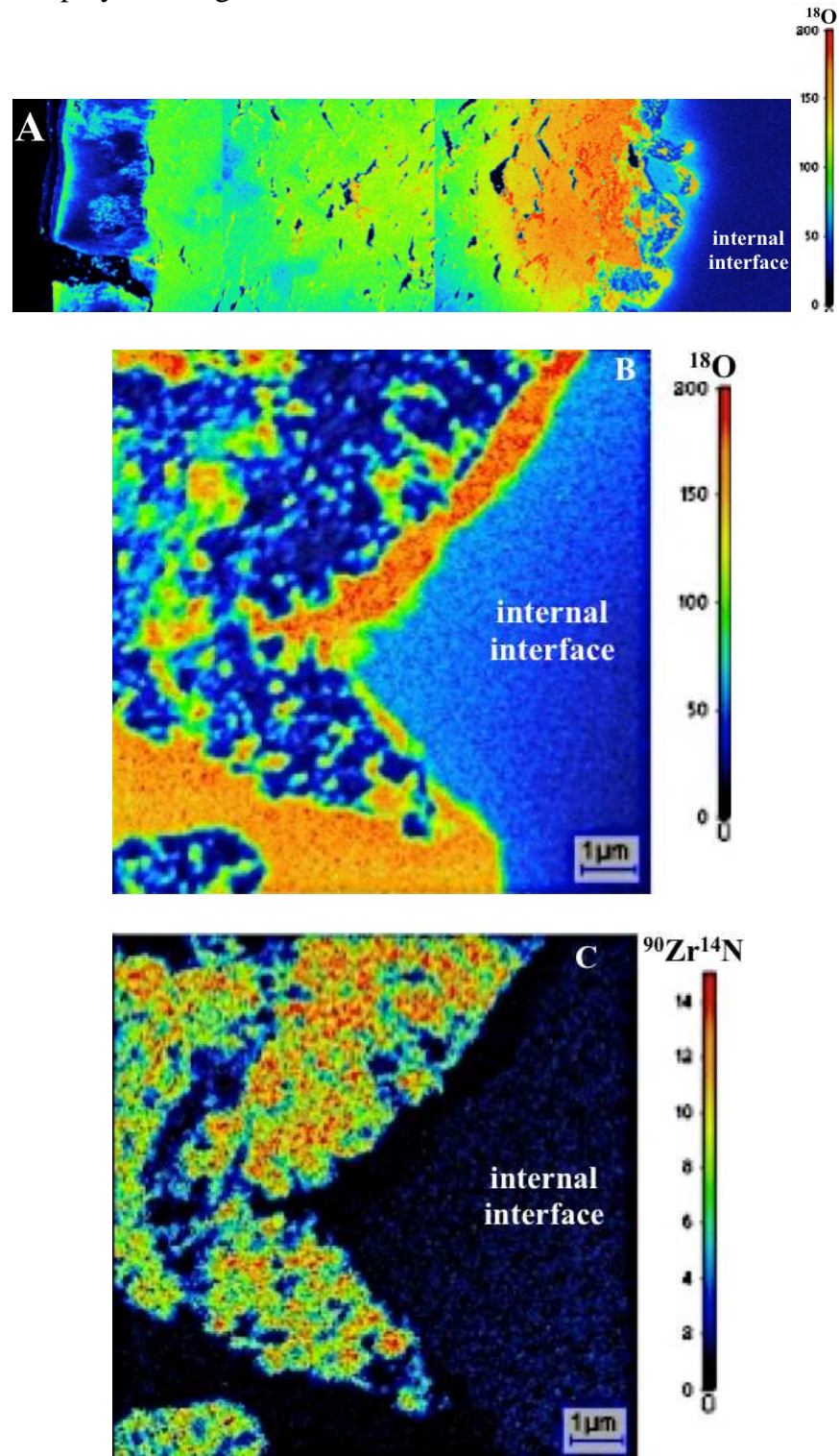

Figure 5 - nanoSIMS analysis during the post-transition stage. A: ${ }^{18} \mathrm{O}$ cartography of a corroded zone from the external to the internal interface, $50 \times 50 \mu \mathrm{m}^{2}$ images gathering, $20 \mathrm{~ms} /$ pixel acquisition time; $B:{ }^{18} \mathrm{O}$ cartography zoom in at the internal interface, $15 \times 15 \mu \mathrm{m}^{2}$ images gathering, $10 \mathrm{~ms} /$ pixel acquisition time; $\mathrm{C}:{ }^{90} \mathrm{Zr}^{14} \mathrm{~N}$ cartography zoom in at the internal interface, $15 \times 15 \mu \mathrm{m}^{2}$ images gathering, $10 \mathrm{~ms} /$ pixel acquisition time

During the post-transition stage, ${ }^{18} \mathrm{O}$ is not observed in the former protective oxide layer that is cracked and consequently became permeable to gases (Figure 5A). The ${ }^{18} \mathrm{O}$ concentration is very low in the $\alpha-\mathrm{Zr}(\mathrm{O})$ solid solution whereas ${ }^{18} \mathrm{O}$ concentration is very high in the porous oxide scale near the metal-oxide interface. In this area, the ${ }^{18} \mathrm{O}$ introduced during the post-transition stage can have been used to oxidize zirconium nitride precipitates previously formed at the metal-oxide interface to create porous $\mathrm{ZrO}$. Figures $5 \mathrm{~B}$ and $5 \mathrm{C}$ show that, close to the internal interface, the corrosion scale is made of ${ }^{90} \mathrm{Zr}^{14} \mathrm{~N}$ precipitates and of areas with high concentration of ${ }^{18} \mathrm{O} . \mathrm{ZrO}_{2}-\mathrm{ZrN}$ phases proportion is not homogeneous in the corroded scale which could explain the brown colour scale observed in Figure 3B. 


\section{Kinetic analysis of the corrosion process}

\subsection{Principle [27-29]}

Let us consider a simple reaction that can be written $A+\sum v_{G} G=v_{B} B+\ldots$ where $A$ is a pure solid phase, $G$ a gas phase, $B$ the solid phase produced along the transformation and $v_{G}$ and $v_{B}$ are the algebraic stoichiometric numbers. This reaction involves two processes, nucleation and growth of the new phase B. The nucleation concerns the surface of the solid and the growth involves both the formation of the new phase $\mathrm{B}$ and the A-B interface between the reactant and the product.

As a general rule, the size of nuclei is small and consequently, B produced by nucleation could be neglected compared with the amount of B produced by growth. As a result, the kinetic rate of the transformation is only the result of the contribution by growth of the new phase B and can be expressed according to E1 provided that some kinetic tests are valid (this point is explained below).

$$
\frac{\mathrm{d}(\Delta \mathrm{m} / \mathrm{S})}{\mathrm{dt}}=\frac{\mathrm{n}_{0}}{2 \cdot \mathrm{S}_{0}} \cdot \Sigma v_{\mathrm{G}} \mathrm{M}_{\mathrm{G}} \cdot \Phi\left(\mathrm{T}, \mathrm{p}\left(\mathrm{O}_{2}\right), \mathrm{p}\left(\mathrm{N}_{2}\right)\right) \cdot \operatorname{Sm}(\mathrm{t})
$$

Where $\Phi$ is the areic rate of growth (in mol. $\mathrm{m}^{-2} \cdot \mathrm{s}^{-1}$ ) defined as the amount of reactant transformed per square meter per second, Sm(t) is a function of time that is related to the extended reaction area where the rate limiting step of growth takes place (in $\left.\mathrm{m}^{2} . \mathrm{mol}^{-1}\right), \mathrm{n}_{0}$ the number of mole of $\mathrm{Zy} 4,2 . \mathrm{S}_{0}=\mathrm{S}$ the total surface of the specimen (two faces $\mathrm{S}_{0}$ react along the process), $\mathrm{M}_{\mathrm{G}}$, the molar mass of oxygen gas.

The reaction rate is measured by means of change in mass with the thermogravimetric apparatus previously described.

The chemical transformation of Zy4 in oxygen and nitrogen partial pressure mixtures involves elementary interface steps and diffusion steps that take place in one or more reaction areas. Reaction areas are assessed according to their location (volume, surface or interface between two phases) and their size could vary or remain stable during the transformation. Elementary steps are made up of intermediate species, which could be ions, molecules or defects.

The validation of the steady state assumption implies that concentration of intermediate species are constant during the process and consequently, no intermediate species, which are created and consumed at interfacial zones, can be detected experimentally.

The validation of the rate-limiting step of growth assumption is possible even if kinetic curves are non reproducible. It implies that, for a transformation that could be divided into elementary steps, it is possible to express the reaction rate with the elementary step controlling the growth process of the new phase $\mathrm{B}$, which is called the rate-limiting (or determining) step. This means that the ratelimiting step has rate constants significantly smaller than those of the other elementary steps.

As a matter of fact, a chemical model with the areic rate of growth $\Phi$ can be established depending on intensive variables and a geometrical model gives the expression of $\mathrm{Sm}(\mathrm{t})$. For isothermal and isobaric conditions, if intensive variables are fixed along the process, $\Phi\left(\mathrm{T}, \mathrm{p}\left(\mathrm{O}_{2}\right), \mathrm{p}\left(\mathrm{N}_{2}\right)\right.$ ) would be constant and consequently only $\mathrm{Sm}(\mathrm{t})$ would vary with time. In heterogeneous reactions, two experimental tests allow validating steady-state approximation and rate-limiting step of growth assumptions.

\subsection{Validation of the steady-state assumption [29]}

This test is based on the measurement of the kinetic rate by means of two independent techniques, thermogravimetry and calorimetry that gives a measure of the heat flow $(\mathrm{dQ} / \mathrm{dt})$.

For steady state conditions, the rate between the kinetic rate and the heat flow is independent of time and given by E2.

$$
\frac{d Q}{d t}=\frac{\Delta H}{\sum_{j} v_{j} M_{j}} \cdot \frac{d \Delta m}{d t}
$$

Where $\Delta \mathrm{H}$ is the enthalpy of reaction, $\mathrm{M}_{\mathrm{j}}$ is the mass of gas $\mathrm{j}$ involved in the balanced reaction and $v_{\mathrm{j}}$ is the algebraic stoichiometric number of gas $\mathrm{j}$. 


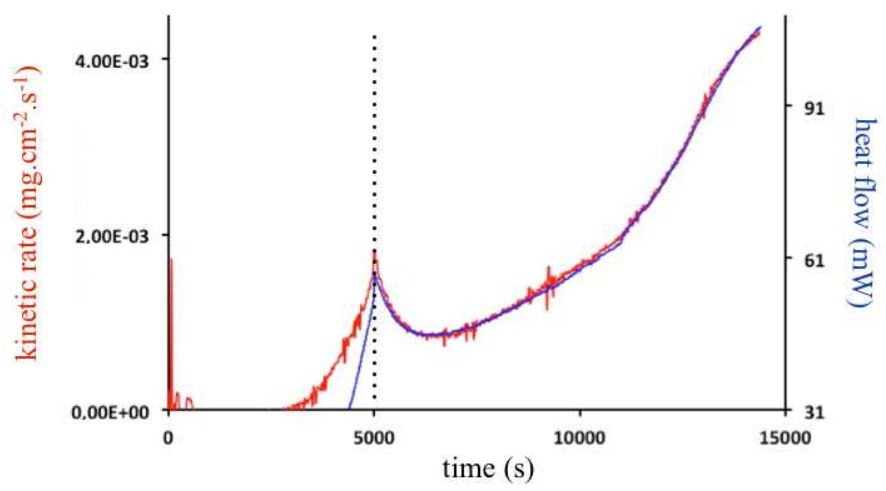

Figure 6 - Steady state test at $850{ }^{\circ} \mathrm{C}$ in $20 \% \mathrm{O}_{2}-80 \% \mathrm{~N}_{2}$ mixture

The experiment for the steady-state test has been done at $850^{\circ} \mathrm{C}$ in a $20 \% \mathrm{O}_{2}-80 \% \mathrm{~N}_{2}$ mixture. The result shown in Figure 6 indicates that, once isobaric and isothermal conditions are reached, the test is validated since the curves of heat flow and change in mass rate are proportional during the pre and post-transition stages.

\subsection{Validation of the rate-limiting step assumption [29]}

To realise this test, also called $\Phi S m$ test, the steady-state assumption has to be validated. This test is based on the method of sudden changes in temperature (or in gas partial pressures) in order to get free of Sm function that has not the time to vary during the jump.

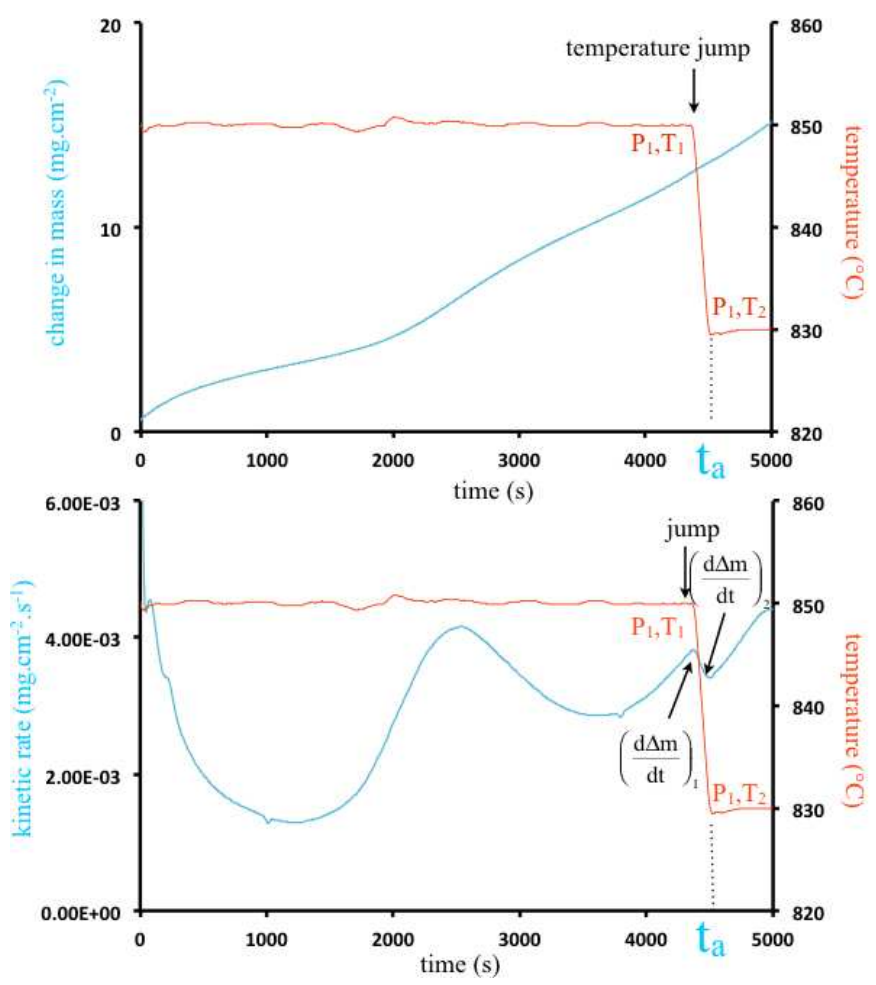

Figure 7 - Principle of the rate-limiting step test ( $\Phi$ Sm test). For this test, He is the only gas present during the heating ramp and once the desired temperature of 850 C is reached, a $20 \% \mathrm{O}_{2}$ and $80 \% \mathrm{~N}_{2}$ mixture is introduced until the end of the experiment. A: change in mass as a function of time for an experiment $\left(t_{a}\right)$; B: kinetic rate obtained for a jump at $t_{b}$

As shown in Figure 7, in a series of experiments conducted up to various changes in mass $\left(t_{a}, t_{b}\right.$, etc.), where $T$ and gases partial pressure conditions are the same, a jump in temperature is made $\left(\mathrm{T}_{1}\right.$ to $\left.\mathrm{T}_{2}\right)$ and the ratio of the kinetic rate after the jump (d $\left.\Delta \mathrm{m} / \mathrm{dt}\right)_{2}$ and before the jump $(\mathrm{d} \Delta \mathrm{m} / \mathrm{dt})_{1}$ is experimentally determined for all changes in mass. We therefore obtain the E3 ratio. 


$$
\frac{\left(\frac{\mathrm{d} \Delta \mathrm{m}}{\mathrm{dt}}\right)_{2}}{\left(\frac{\mathrm{d} \Delta \mathrm{m}}{\mathrm{dt}}\right)_{1}}=\frac{\Phi(\mathrm{T}=830) \cdot \operatorname{Sm}\left(\mathrm{t}_{\mathrm{a}}\right)}{\Phi(\mathrm{T}=850) \cdot \operatorname{Sm}\left(\mathrm{t}_{\mathrm{a}}\right)}=\frac{\Phi(\mathrm{T}=830) \cdot \operatorname{Sm}\left(\mathrm{t}_{\mathrm{b}}\right)}{\Phi(\mathrm{T}=850) \cdot \operatorname{Sm}\left(\mathrm{t}_{\mathrm{b}}\right)}=\frac{\Phi(\mathrm{T}=830)}{\Phi(\mathrm{T}=850)}
$$

Sm terms are eliminated. The values of the ratio obtained for different changes in mass must be identical during the process to validate the rate-limiting step of growth assumption.

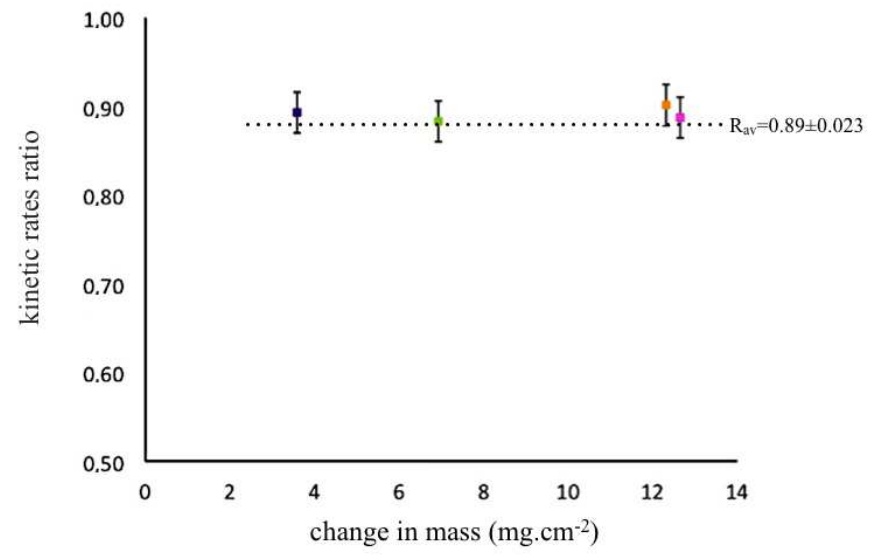

Figure 8 - $\Phi \mathrm{Sm}$ test in $20 \% \mathrm{O}_{2}-80 \% \mathrm{~N}_{2}$ mixture with temperature jumps from $850^{\circ} \mathrm{C}$ to $830^{\circ} \mathrm{C}$

In Figure 8, $\Phi \mathrm{Sm}$ test has been realised for $\mathrm{Zy} 4$ in $20 \% \mathrm{O}_{2}-80 \% \mathrm{~N}_{2}$ gas mixture during the post-transition stage with temperature jump from $850^{\circ} \mathrm{C}$ to $830^{\circ} \mathrm{C}$. It can be seen that values of the ratio obtained for different changes in mass are approximately equal, which means that $\Phi S m$ test is also validated even if the kinetic curves are not reproducible.

For this test, $\mathrm{He}$ is the only gas present during the heating ramp and once the temperature of $850^{\circ} \mathrm{C}$ is reached, a $20 \% \mathrm{O}_{2}-80 \% \mathrm{~N}_{2}$ gas mixture is introduced, after $6 \mathrm{~min}$ homogenisation of the pressure in the furnace, until the end of the experiment. We have done these series of experiment at the beginning of the study because we would like to operate as Duriez et al. experiments [1] in order to compare our results. But when comparing the curves, the kinetic transition was not reproducible at all and took place at a really short time after reactive gas introduction. It was consequently not possible to define a mechanism with this way to operate and because the sample reacted randomly with the reactive gas. However, as the rate limiting step test can be done with non-reproducible curves, using these series of experiments has no influence on the conclusion made concerning the validity of the test.

\section{Study of variation of $\Phi$ with gases partial pressure}

This study is a help to determine which elementary step of the transformation is the rate-limiting step knowing variation of its areic rate of growth with oxygen and nitrogen partial pressure.

As shown in Figure 9, the study consists in realising a series of experiments where, for the same change in mass, different jumps of $\mathrm{p}\left(\mathrm{O}_{2}\right)$ and $\mathrm{p}\left(\mathrm{N}_{2}\right)$ are done: for a fixed $\mathrm{p}\left(\mathrm{O}_{2}\right)$, the value of $\mathrm{p}\left(\mathrm{N}_{2}\right)$ is changed and, for a fixed $\mathrm{p}\left(\mathrm{N}_{2}\right)$, the value of $\mathrm{p}\left(\mathrm{O}_{2}\right)$ is changed.

By scanning a range of given pressures, it is possible to determine the variation of $\Phi$.

The study of variation of $\Phi$ with oxygen partial pressure has been done for a change in mass of 10 mg.cm ${ }^{-2}$ with initial oxygen and nitrogen partial pressure conditions of $\mathrm{p}\left(\mathrm{O}_{2}\right)=20 \mathrm{kPa}$ and $\mathrm{p}\left(\mathrm{N}_{2}\right)=80 \mathrm{kPa}$ at $850^{\circ} \mathrm{C}$ and, the study of variation of $\Phi$ with nitrogen partial pressure has been done for a change in mass of $8 \mathrm{mg} \cdot \mathrm{cm}^{-2}$ with initial gases partial pressure conditions of $\mathrm{p}\left(\mathrm{O}_{2}\right)=20 \mathrm{kPa}, \mathrm{p}\left(\mathrm{N}_{2}\right)=5 \mathrm{kPa}$ and $\mathrm{p}(\mathrm{He})=75 \mathrm{kPa}$ at $850^{\circ} \mathrm{C}$. The areic rate of growth $\Phi$ does not depend on the nitrogen partial pressure (Figure 11) but is highly influenced by the oxygen partial pressure (Figure 10). 

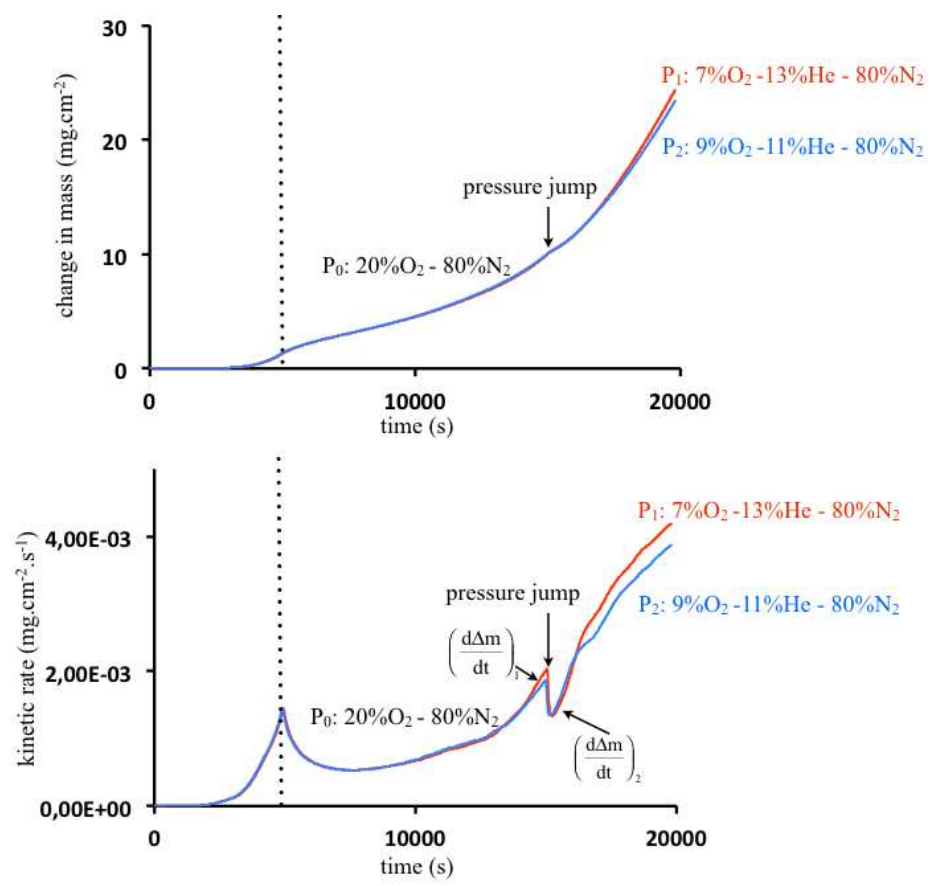

Figure 9 - Principle of the study of the variation of the areic rate of growth $\Phi$ as a function of partial pressure. In this experiment, a $20 \% \mathrm{O}_{2}$ and $80 \% \mathrm{~N}_{2}$ mixture is introduced at ambient temperature and for a fixed value of $p\left(\mathrm{~N}_{2}\right), \mathrm{p}\left(\mathrm{O}_{2}\right)$ is changed at a change in mass of 8 mg.cm ${ }^{-2}$.

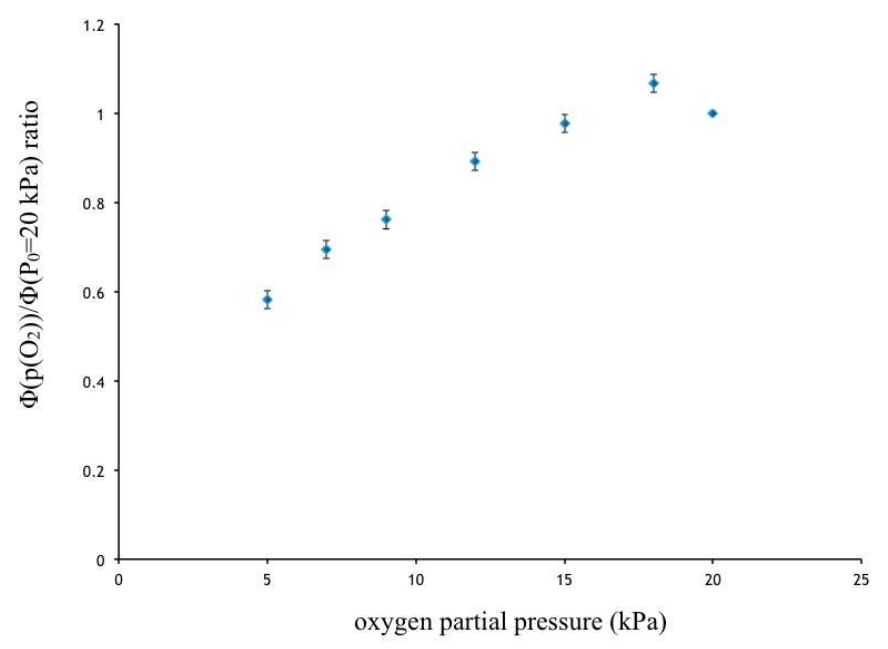

Figure 10 - Variation of $\Phi$ ratio as a function of oxygen partial pressure, initial conditions: $p\left(\mathrm{O}_{2}\right)=20 \mathrm{kPa}$ and $\mathrm{p}\left(\mathrm{N}_{2}\right)=80 \mathrm{kPa}$ 


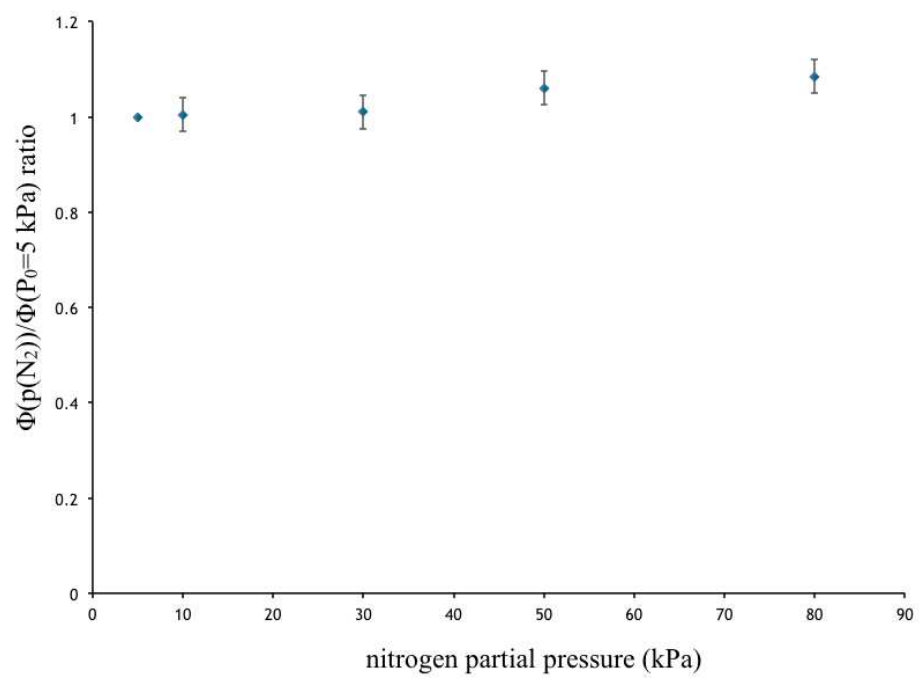

Figure 11 - Variation of $\Phi$ ratio as a function of nitrogen partial pressure, initial conditions: $p\left(\mathrm{O}_{2}\right)=20 \mathrm{kPa}$ and $\mathbf{p}\left(\mathrm{N}_{2}\right)=5 \mathrm{kPa}$ and $\mathrm{p}(\mathrm{He})=75 \mathrm{kPa}$

\section{DISCUSSION}

\section{Sequence of events proposed during the process}

From the various results presented in the experimental part, the corrosion process of $\mathrm{Zy} 4$ in oxygen and nitrogen mixture at $850^{\circ} \mathrm{C}$ can be described as follows:

- during the pre-transition stage, $\mathrm{Zy} 4$ is oxidized to form a dense oxide layer. This reaction is thermodynamically the most favourable and consequently the decrease of the kinetic rate is due to oxygen vacancy controlling diffusion of the oxide layer growth (diffusion rate-limiting step). It has been seen that small quantities of zirconium nitride can precipitate into the zirconia layer but this $\mathrm{ZrN}$ formation has no influence on the change in mass and consequently, on the nature of the rate-determining step. From a thermodynamic point of view, the precipitation of $\mathrm{ZrN}$ is possible near the metal oxide interface at very low nitrogen equivalent partial pressures $\left(\mathrm{p}\left(\mathrm{N}_{2}\right)>6.66 .10^{-25} \mathrm{~atm}\right)$. This is due to the very low oxygen pressure at $\mathrm{Zr} / \mathrm{ZrO}_{2}$ equilibrium $\left(\mathrm{p}\left(\mathrm{O}_{2}\right)=5.09 .10^{-42}\right.$ atm $)$. Further to a dissociation process by progressive ionising with electrons of the zirconia layer [30], anions $\mathrm{N}^{3-}$ could be incorporated into the zirconia forming a solid solution described in $[31,32]$. Once $\mathrm{ZrN}$ has precipitated at the internal interface, where oxygen vacancy concentration is high, its oxidation by the oxygen flow could be the origin of the cracks because of the increase of molar volume induced by the reaction. Cracks formation by oxidation of $\mathrm{ZrN}$ precipitates could thus explain why the kinetic transition time is shorter in oxygennitrogen mixture compared with oxygen-helium mixture;

- during post-transition stage, steady state and rate-limiting step of growth assumptions are valid, which means respectively that (i) there is only one term in the kinetic rate equation and oxygen and nitrogen flows are never limiting and, (ii) there is a rate-determining step which control the kinetic rate.

The characterization part shows that three reactions take place during the post-transition stage:

(1) Formation of zirconium nitride with the $\alpha-\operatorname{Zr}(\mathrm{O})$ phase once cracks appears through the dense zirconia layer to form $\mathrm{ZrN}$ and dense $\mathrm{ZrO}_{2}$ mixtures at metal oxide interface, $\mathrm{ZrN}$ precipitates are then put in traction between dense $\mathrm{ZrO}_{2}$ phases and cracks on $\mathrm{ZrN}$ precipitates appear parallel to the interface,

(2) Oxidation of $\mathrm{ZrN}$ to form microcracks in $\mathrm{ZrO}_{2}$. This reaction corresponds to the corrosion front progression. Indeed the nitrogen released by this reaction is trapped between $\mathrm{ZrO}_{2}$ and $\alpha-\mathrm{Zr}(\mathrm{O})$, which leads to $\alpha-\mathrm{Zr}(\mathrm{O})$ phase nitriding. During oxidation of $\mathrm{ZrN}$, if nitrogen flow is never limiting, nitrogen could not be trapped between $\mathrm{ZrO}_{2}$ and $\mathrm{ZrN}$ phases to form $\mathrm{ZrO}_{\mathrm{x}} \mathrm{N}_{\mathrm{y}}$ or $\mathrm{Zr}_{2} \mathrm{ON}_{2}$ and $\mathrm{Zr}_{3} \mathrm{~N}_{4}$ as described in the literature. $\mathrm{ZrN}$ seems to act as a catalyst: its formation is necessary to accelerate the corrosion process. Consequently, $\mathrm{p}\left(\mathrm{N}_{2}\right)$ has necessarily a small an influence to maintain the metal transformation in oxygen-nitrogen mixture (we see in Figure 11 that the ratio has a small increase with nitrogen partial pressure),

(3) Oxidation of $\mathrm{Zr}$ to form the solid solution $\alpha-\mathrm{Zr}(\mathrm{O})$. 
Supposing that nitriding of $\alpha-\operatorname{Zr}(\mathrm{O})$ as well as introduction of gaseous oxygen in the interstitial lattice of $\alpha-\mathrm{Zr}$ has faster kinetic rate than $\mathrm{ZrN}$ oxidation, the rate-limiting step is part of $\mathrm{ZrN}$ oxidation reaction and nitriding of $\alpha-\mathrm{Zr}(\mathrm{O})$ phase will depend on nitrogen released by oxidation of $\mathrm{ZrN}$, the kinetic rate of both reactions is then proportional.

2. Geometrical model for the expression of $\operatorname{Sm}(\mathrm{t})$

It has been seen in the characterization part that the kinetic transition is a non-uniform process and that post-transition regions progress in an isotropic way, which leads to a half ellipsoidal shape of the corroded zones (Figure 3B). As a result, during the post-transition stage, the mass gain is the result of two contributions: one due to the dense zirconia growth in the pre-transition region, which is parallel to the initial surface, whereas the other is due to the regions that have passed the kinetic transition, whose growth is isotropic. As far as the number of attacked regions (post-transition regions) significantly increases, contribution of pre-transition regions becomes negligible compared to post-transition one. Consequently, acceleration of the corrosion process is only due to propagation of attacked regions and the increase of the half ellipsoidal shape areas. Ellipsoidal shape of the corroded zone gives information concerning the nature of the rate-determining step. Indeed, the rate-determining step corresponds to an interfacial reaction.

From a phenomenological point of view, the kinetic model best adapted to described behaviour of post-transition regions is a surface nucleation and growth model according to Mampel' assumptions [33]. Mathematical calculations have to be applied to explain the shape of the kinetic curves assuming that (i) post-transition regions appear at random at the sample surface depending on temperature, oxygen and nitrogen partial pressure, alloy composition, mechanical stresses, etc. (ii) the growth kinetic of post-transition regions is controlled by an interfacial reaction.

In that way, if the number of corroded regions per unit of time and surface area characterized by a nucleation frequency, which depends on the local thermodynamic variables, is high then, the surface of the sample is rapidly covered.

\section{CONCLUSION}

The kinetic analysis of the highly complex reactive system of $\mathrm{Zy} 4$ corrosion in mixed oxygen and nitrogen atmosphere has been made at $850^{\circ} \mathrm{C}$. It has been possible to verify that both steady-state assumption and the existence of an elementary step controlling the growth process are well established during the post-transition stage.

Thanks to characterizations, a sequence of events during transformation has been proposed as well as the nature of the rate-limiting step (interfacial reaction). In addition, thanks to the study of the areic rate of growth variation as a function of gases partial pressure, it is possible to determine which elementary step of the transformation is the rate-limiting step.

Experimental curves can thus be described by cracks initiation by $\mathrm{ZrN}$ catalyst formation or stress relaxation phenomena followed by growth of porous $\mathrm{ZrO}_{2}$. In addition, it has been seen that an analogy to nucleation and growth models allows the calculation of the kinetic rate versus time and this point will be the topic of a further paper.

The final step would be to implement the kinetic model in the severe accident code ASTEC, jointly developed by IRSN and GRS to assess the whole sequence of a severe accident, with the ultimate goal of computing fuel assembly degradation in air ingress situations.

\section{ACKNOWLEDGEMENTS}

The authors wish to express their gratitude to Christian Duriez for its precious help and stimulating discussions.

\section{REFERENCES}

[1] C. Duriez et al., J. Nucl. Mater. 2008, 380, 30-45.

[2] C. Duriez et al., Nucl. Eng. Des. 2009, 239, 244-253.

[3] M. Steinbrück, J. Nucl. Mater. 2009, 392, 531-534.

[4] M. Steinbrück, presented at HTCPM, Les Embiez, France, 2012.

[5] O. Coindreau et al., J. Nucl. Mater. 2010, 405, 207-215.

[6] E.B. Evans et al., presented at Metallurgical Society of AIME Symposium on High Temperature Gas-Metal Reactions in Mixed Environments, 1972.

[7] C.J. Rosa, W.W. Smeltzer, Z. Metallkde 1980, 470-474.

[8] M. Lerch, J.Am. Ceram. Soc. 1996, 79, 2641-2644.

[9] I. Idarraga et al., J. Nucl. Mater. 2012, 421, 160-171.

[10] N. Claussen et al., J. Am. Ceram. Soc. 1978, 369-370.

[11] Y. Cheng, D.P. Thompson, J.Am. Ceram. Soc. 1991, 74, 1135-1138.

[12] Y. Cheng, D.P. Thompson, J. Am. Ceram. Soc. 1993, 76, 683-688.

[13] M. Lerch et al., J. Mater. Sci. Lett. 1996, 15, 2127-2129.

[14] M. Lerch et al., Solid State Ionics 1997, 95, 87-93. 
[15] M. Lerch, O. Rahäuser, J. Mater. Sci. 1997, 32, 1357-1363.

[16] T.-J. Chung et al., J.Am. Ceram. Soc. 1999, 11, 3193-3199.

[17] T.J. Chung et al., J.Am. Ceram. Soc. 2001, 84, 172-178.

[18] S. Gutzov, M. Lerch, Ceram. Int. 2007, 33, 147-150.

[19] M. Lerch et al., Prog. Solid State Chem. 2009, 37, 81-131.

[20] M. Steinbrück, M. Jung, presented at ICAPP, Nice, France, 2011.

[21] M. Lerch et al., Z. anorg. allg. Chem 1996, 622, 367-372.

[22] H. Wiame et al., J. of Euro. Ceram. Soc. 1998, 18, 1293-1299.

[23] D.I. Bazhanov et al., J. Appl. Phys. 2005, 97, 1-6.

[24] G.L.N. Reddy et al., Appl. Surf. Sci. 2007, 253, 7230-7237.

[25] H.O. Pierson, Noyes Publications, 1996.

[26] I. Idarraga et al, to appear in Oxid. Met., DOI 10.1007/s11085-012-9331-5

[27] M. Soustelle, M. Pijolat, Solid State Ionics 1997, 95, 33-40.

[28] M. Pijolat et al., Thermochim. Acta 2005, 439, 86-93.

[29] M. Pijolat, M. Soustelle, Thermochim. Acta 2008, 478, 34-40.

[30] I. Valov, J. Janek, Solid State Ionics 2006, 177, 1619-1624.

[31] J.C. Gilles, CNRS 1962, 352, 2118-2121.

[32] R. Collongues et al., Mat. Res. Bull. 1967, 2, 837-848.

[33] M. Tupin, Mater. Sci. Forum 2004, 461-464, 139-146. 